\title{
Variación genética y flujo de genes entre poblaciones de Crocodylus acutus (Crocodylia: Crocodylidae) en tres ríos del Pacífico Central, Costa Rica
}

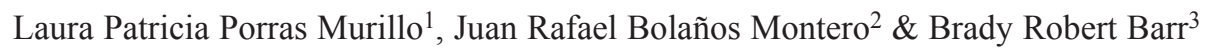 \\ 1. Programa Regional en Manejo de Vida Silvestre para Mesoamérica y el Caribe. Apdo 1350-3000 Heredia, Costa Rica; \\ lauporras@gmail.com \\ 2. Asociación de Especialistas en Cocodrilos-Costa Rica; cocodrilo1@gmail.com \\ 3. National Geographic Chanel; bradybarr@aol.com
}

Recibido 27-IV-2007. Corregido 08-V-2008. Aceptado 20-V-2008.

\begin{abstract}
Genetic variation and gene flow among populations of Crocodylus acutus (Crocodylia: Crocodylidae) in three rivers of Central Pacific, Costa Rica. The crocodylid Crocodylus acutus is found in the Central Pacific of Costa Rica only in small populations, and the species is protected by law. RAPD was used to analyze 70 DNA samples of Crocodylus acutus from the rivers Jesus Maria, Tarcoles and Tusubres in the Central Pacific of Costa Rica in order to estimate genetic diversity, differentiation among populations, gene flow and genetic distance between them. Genetic diversity was low in the three rivers, $\mathrm{H}=0.2201$ in the Jesus Maria river, 0.2358 in the Tarcoles river and 0.2589 in the Tusubres river. Among the three populations there is a metapopulational dynamic $(\mathrm{GST}=0.0367)$, mainly between the populations of the Jesus Maria and Tarcoles rivers. The value of gene flow $(\mathrm{Nm}=13.1361)$ and the number of individuals reported for each river in 2004 suggests that the population of the Tarcoles river is the source and those from Jesus Maria and Tusubres are the drains. There was a direct relationship between the genetic distance and the geographical distance $(\mathrm{z}=1.1449, \mathrm{r}$ $=0.9731, \mathrm{p}<0.0010$ ). A conservation strategy for these crocodiles must consider the existence of the metapopulation between the three rivers and the importance of studying the genetics of the American Crocodile in the rest of the Pacific coast of Costa Rica, as well as over the entire distribution range of this species. Rev. Biol. Trop. 56 (3): 1471-1480. Epub 2008 September 30.
\end{abstract}

Key words: Crocodylus acutus, genetic diversity, gene flow, genetic distance, metapopulation.

Según la Unión Internacional para la Conservación de la Naturaleza (Anónimo 1999) las poblaciones de Crocodylus acutus (Cuvier 1807) se encuentran en estado vulnerable a lo largo de su distribución y está listada en la Ley de Conservación de Vida Silvestre de Costa Rica (Anónimo 1998) como especie en peligro de extinción. Esto ha estimulado la realización de estudios para determinar el estado real de la especie, pero poco se ha investigado acerca de la dinámica genética de sus poblaciones, aspecto fundamental para establecer políticas de manejo que garanticen su futuro.

En el caso del Pacífico Central de Costa Rica, anteriormente se han registrado poblaciones pequeñas de cocodrilos en los ríos Tusubres y Jesús María, en este último la población presenta una estructura poblacional que no permite la viabilidad a largo plazo (Piedra 2000, Porras 2004). Sobre esto, Piedra (2000) discute la posibilidad de que la población del río Jesús María sea una subpoblación incluida dentro de un complejo metapoblacional alimentado por los cocodrilos del río Tárcoles. Piedra (2000) también señala que esta puede ser la explicación para que la que la población del río Jesús María no haya desaparecido y se mantenga a corto o mediano plazo.

Según Hedrick (2000) en la mayoría de las especies, las poblaciones están subdivididas en 
pequeñas unidades debido a factores geográficos, ecológicos, etológicos, y migratorios. Las estrategias de apareamiento son las que determinan las diferencias genéticas entre y dentro de las poblaciones (Chesser 1991). En el caso de C. acutus, es posible que algunos individuos no logren establecer territorio en su hábitat original durante la época de cortejo y apareamiento, por lo que migran hacia otros hábitat en busca de oportunidad para reproducirse. El movimiento de individuos es uno de los factores que trae consigo flujo genético entre poblaciones (Blouin-Demers y Weatherhead 2002) y es altamente beneficioso sobre todo para poblaciones pequeñas, como es el caso del río Jesús María, porque disminuye el riesgo de la depresión por endogamia y deriva genética (Konuma et al. 2000).

El interés por el estudio del flujo de genes ha aumentado debido a su relevancia para la conservación de especies (Parker et al. 1998), no obstante medir este y otros parámetros genéticos es difícil (Slatkin 1987). En la última década, la técnica molecular de ADN Polimórfico Amplificado al Azar (RAPD) ha sido una de las más usadas debido a su simplicidad, aplicabilidad y bajo costo, además de que permite utilizar muchos marcadores con pequeñas cantidades de ADN (Bardakci 2001).

Pocas investigaciones se han llevado a cabo sobre aspectos genéticos de poblaciones de crocodílidos. Para C. acutus específicamente se hizo un trabajo sobre variación genética en tres poblaciones usando la técnica de electroforésis (Menzies y Kushlan 1991) y últimamente se han diseñado microsatélites para su uso en futuros estudios (Fitzsimmons et al. 2000). En otras especies de crocodílidos como Alligator mississipiensis, C. niloticus, Osteolaemus tetraspis, C. moreletti, A. sinensis, C. jonhstoni, C. porosus y C. mindorensis se han evaluado aspectos como flujo genético, variación genética y estructura genética (Davis et al. 2000, Flint et al. 2000, Ray et al. 2000, Anónimo 2002, Dever et al. 2002, Wu et al. 2002).

Este trabajo tiene por objetivo estimar la variación genética entre y dentro de poblaciones así como el grado de diferenciación y el flujo de genes entre las poblaciones de C. acutus de los ríos Jesús María, Tárcoles y Tusubres en el Pacífico Central de Costa Rica.

\section{MATERIALES Y MÉTODOS}

Área de estudio: Los ríos Jesús María, Tárcoles y Tusubres están ubicados en el Pacífico Central de Costa Rica (9 55'55'9॰32’10” N, 8439'41"'-84³3'12” O) dentro del Área de Conservación Pacífico Central (ACOPAC). La distancia entre la desembocadura del río Jesús María y el río Tárcoles es de $12.10 \mathrm{~km}$, y entre la del río Tárcoles y la del río Tusubres de $43.40 \mathrm{~km}$. Los tres ríos desembocan en el mar y tienen manglar asociado.

La población de cocodrilos de los tres ríos ha sido estudiada anteriormente. Para el río Tárcoles se ha estimado una abundancia relativa de $30.08 \pm 5.33 \mathrm{ind} / \mathrm{km}$ (Piedra 2000) y $9.22 \pm 2.49 \mathrm{ind} / \mathrm{km}$ (Porras 2004), para el río Jesús María la abundancia relativa registrada es de $2.39 \pm 0.01 \mathrm{ind} / \mathrm{Km}$ (Piedra 2000) y 1.51 $\pm 0.48 \mathrm{ind} / \mathrm{km}$ (Porras 2004) y el río Tusubres presenta una abundancia de cocodrilos de 8.14 $\pm 0.21 \mathrm{ind} / \mathrm{Km}$ (Piedra 2000) y $5.58 \pm 0.83 \mathrm{ind} /$ km (Porras 2004).

Captura y recolecta de sangre: Los animales se capturaron durante recorridos nocturnos hechos de junio a diciembre del 2003. Se siguió el procedimiento usado por Bolaños et al. (1997). Cada animal capturado fue marcado, medido y sexado.

Se extrajo $1 \mathrm{ml}$ de sangre en el caso de los individuos neonatos y $3 \mathrm{ml}$ en el caso de los jóvenes, subadultos y adultos. La muestra se obtuvo del seno sanguíneo ubicado detrás de la cabeza sobre la espina dorsal. La sangre se colocó en tubos de ensayo con EDTA y se trasladó al laboratorio en una hielera a $5{ }^{\circ} \mathrm{C}$ aproximadamente.

Extracción y amplificación de ADN: Para la extracción del ADN de las muestras de sangre se utilizó el Wizard Genomic DNA Purification Kit de Promega. Se probaron 21 
marcadores de los kit A y B de Operon ${ }^{\circledR}$ (RAPD ${ }^{\circledR} 10$ mer Kits). Para el análisis de todas las muestras de ADN sólo se tomaron en cuenta los marcadores que presentaron polimorfismo.

El ADN obtenido de todas las muestras de sangre se amplificó utilizando 2X PCR Master Mix de Fermentas ${ }^{\circledR}$ al que se le agregó 5 u/ $\mu$ l de Taq DNA Polymerase de Fermentas ${ }^{\circledR}$ para obtener mejor definición de las bandas. La amplificación se hizo en un volumen total de $25 \mu \mathrm{l}$ que contenía $12.5 \mu \mathrm{l}$ de $2 \mathrm{X}$ PCR Master Mix + Taq DNA Polymerase, $10 \mu \mathrm{l}$ de $\mathrm{H}_{2} \mathrm{O}$ desionizada, $1 \mu \mathrm{l}$ de marcador y $1.5 \mu \mathrm{l}$ de ADN. Se utilizó un termociclador GeneAmp PCR System 9600 de Perkin Elmer® con los siguientes parámetros: predesnaturalización a $94{ }^{\circ} \mathrm{C}$ por 1.5 minutos, seguido de 40 ciclos de $94{ }^{\circ} \mathrm{C}$ por 30 segundos, $35^{\circ} \mathrm{C}$ por 30 segundos y $72{ }^{\circ} \mathrm{C}$ por 1 minuto y una extensión de $72{ }^{\circ} \mathrm{C}$ por 3 minutos.

Los productos de amplificación fueron visualizados junto con el marcador de peso molecular GeneRuler ${ }^{\mathrm{TM}} 1 \mathrm{~Kb}$ DNA Ladder de Fermentas, en geles de agarosa al 1.2\% teñidos con de bromuro de etidio al $0.01 \mathrm{mg} /$ $\mathrm{ml}$, en búfer TBE y corrido a 90 voltios por 2 minutos y luego 60 voltios por 20 minutos. Las fotografías se tomaron utilizando un transluminador de luz ultravioleta marca BioRad MiniTransluminator y una cámara digital Nikon Coolpix 2100 con un filtro Tiffen 15 "deep yellow". La información de cada fotografía fue clasificada y almacenada en una base de datos en un formato binario.

Análisis de datos: Para cada población y para el conjunto de poblaciones se calculó la diversidad genética ( $\mathrm{H}$ (heterocigocidad) de Nei). Para evaluar la variación genética dentro y entre poblaciones se calcularon los valores de $\mathrm{H}_{\mathrm{S}}$ y $\mathrm{H}_{\mathrm{T}}$ y el grado de división genética entre las poblaciones (Coeficiente de diferenciación $\mathrm{G}_{\mathrm{ST}}$, Nei 1987). A partir de este coeficiente se calculó el flujo genético Nm (McDermott y McDonald 1993) para estimar el número de individuos que migran entre las poblaciones por generación. También se obtuvieron los valores de distancia genética no sesgados (Nei 1978) entre poblaciones a partir de los cuales se construyó un dendrograma basado en el método UPGMA. Para estos análisis se usó el programa POPGENE versión 1.32 (Yeh y Boyle 1997). Se hizo la prueba de Mantel para determinar la relación entre la distancia genética y la distancia geográfica entre las poblaciones utilizando el programa IBD (Bohonak 2002). Para determinar la relación entre todos los individuos muestreados se construyó un dendrograma basado en el método SAHN y utilizando el coeficiente de similitud de Dice (1945) en el programa NTSYSpc versión 2.11 (Rohlf 2003).

\section{RESULTADOS}

Amplificación: Se utilizó un total de 70 muestras de ADN de C. acutus, 16 corresponden al río Jesús María, 38 al río Tárcoles y 16 al río Tusubres. De los marcadores probados, solamente siete fueron utilizados para analizar todas las muestras de ADN considerando la presencia de polimorfismo y el volumen disponible del marcador para realizar todas las amplificaciones.

Variación y flujo genético: Los valores de diversidad genética para cada población son bajos y no hubo diferencias entre ellos $(\mathrm{H}=1.95, \mathrm{p}=0.38)$. La diversidad genética total también fue baja y similar a la registrada para cada río (Cuadro 1).

La variación genética dentro $\left(\mathrm{H}_{\mathrm{S}}\right)$ y entre poblaciones $\left(\mathrm{H}_{\mathrm{T}}\right)$ fue baja (Cuadro 2). Esto causa que el porcentaje de diferenciación genética $\left(\mathrm{G}_{\mathrm{ST}}\right)$ entre las poblaciones sea apenas de $3.4 \%$ lo que refleja muy poca diferenciación entre las poblaciones (Yeh 2000). El valor de flujo genético $(\mathrm{Nm})$ muestra que aproximadamente 13 individuos migran por generación entre las tres poblaciones estudiadas.

La poca variación encontrada también se refleja en la distancia genética entre las poblaciones, que en general es de 0.01 y además tuvo relación directa $(\mathrm{z}=1.1449, \mathrm{r}=0.9731, \mathrm{p}<$ 0.0010 , datos obtenidos de 1000 simulaciones) con la distancia geográfica que separa a las desembocaduras de los ríos (Cuadro 3). 
CUADRO 1

Diversidad genética $(H)$ de tres poblaciones de C. acutus en el Pacifico Central de Costa Rica

TABLE 1

Genetic diversity (H) of three populations of C. acutus in the Pacific Central of Costa Rica

$\begin{array}{lcccc} & \text { Jesús María } & \text { Tárcoles } & \text { Tusubres } & \text { Total } \\ \text { H } & 0.2201 & 0.2358 & 0.2589 & 0.2452 \\ \text { Desviación estándar } & 0.1950 & 0.1870 & 0.2041 & 0.1882 \\ \text { Porcentaje de loci polimórficos } & 68.09 & 97.87 & 76.60 & 100\end{array}$

CUADRO 2

Análisis de diversidad genética, grado de diferenciación genética y flujo de genes entre tres poblaciones de C. acutus en el Pacifico Central de Costa Rica

TABLE 2

Analysis of genetic diversity, coefficient of gene differentiation and gene flow between three populations of $\mathrm{C}$. acutus in the Central Pacific of Costa Rica

$\begin{array}{lccccc} & \mathrm{N} & \mathrm{H}_{\mathrm{T}} & \mathrm{H}_{\mathrm{S}} & \mathrm{G}_{\mathrm{ST}} & \mathrm{Nm} \\ \text { Media } & 70 & 0.2473 & 0.2383 & 0.0367 & 13.1361 \\ \text { Desviación estándar } & & 0.0363 & 0.0339 & & \end{array}$

CUADRO 3

Distancia geográfica y genética entre tres poblaciones de C. acutus en el Pacífico Central de Costa Rica

TABLE 3

Geographic and genetic distance between three populations of $\mathrm{C}$. acutus in the Central Pacific of Costa Rica

$\begin{array}{lccc}\text { Población } & \text { Jesús María } & \text { Tárcoles } & \text { Tusubres } \\ \text { Jesús María } & & 12.1 & 55.5 \\ \text { Tàrcoles } & 0.0080 & & 43.4 \\ \text { Tusubres } & 0.0113 & 0.0097 & \end{array}$

Arriba de la diagonal aparece la distancia geográfica en $\mathrm{Km}$ y abajo la distancia genética.
Aunque hubo poca diferenciación genética entre las poblaciones de cocodrilos de los tres ríos, el dendrograma de la Fig. 1 basado en la distancia genética entre las poblaciones, muestra como los ríos Jesús María y Tárcoles están agrupados y queda excluido el río Tusubres ya que hay una diferencia de $13 \%$ entre éste y las otras dos poblaciones, lo que a su vez significa que el movimiento de individuos es mayor entre los dos primeros ríos.

El análisis de los individuos involucrados en este estudio, refleja que todos los individuos son similares en aproximadamente un 50\% $\mathrm{y}$ algunos provenientes de las tres poblaciones (THJ443, JXN508, JXN509, TUMJ600) 


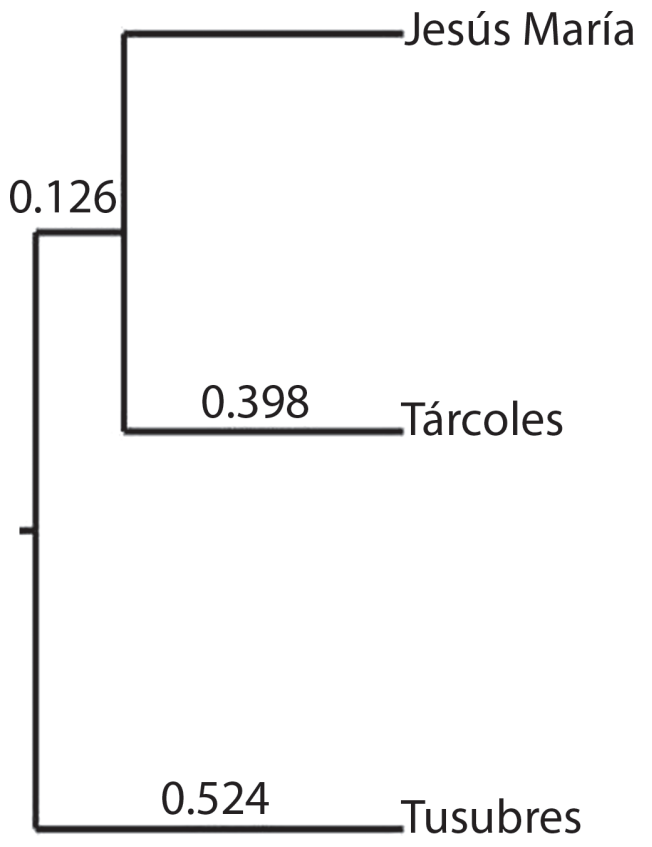

Fig. 1. Dendrograma UPGMA basado en la distancia genética entre tres poblaciones de C. acutus.

Fig. 1. UPGMA dendrogram based in genetic distance between three populations of $C$. acutus.

tienen un alto porcentaje de similitud entre sí (aproximadamente 85\%). Además no hay un agrupamiento claro entre los individuos de una misma población (Fig. 2). Los individuos que resultaron ser genéticamente iguales, o sea con un valor de similitud igual a 1, (TUMJ614 y TUMHJ615) son neonatos procedentes, posiblemente, del mismo nido.

\section{DISCUSIÓN}

Los valores de diversidad genética encontrados para las tres poblaciones estudiadas son relativamente mayores a los registrados anteriormente para $C$. acutus en Jamaica $0.055 \pm 0.009$, Florida $0.117 \pm 0.017$ y República Dominicana $0.158 \pm 0.039$ (Menzies y Kushlan 1991). Esta diferencia puede deberse a que las poblaciones continentales tienen mayor variación genética que las insulares (Frankham 1996) y a los distintos métodos moleculares utilizados.

Todas las especies de crocodílidos están estrechamente relacionadas (Norell 1989) y es normal encontrar bajos niveles de variación genética (Flint et al. 2000), sin embargo la diversidad genética de $C$. acutus debería aumentar en relación con otras especies debido a la variabilidad de hábitat en los cuales se encuentran (Menzies y Kushlan 1991) y a su amplio ámbito de distribución (Frankham 1996).

La diversidad genética encontrada en este estudio puede considerarse baja si se toma en cuenta que para C. moreletii, especie cercana genéticamente a C. acutus (Brochu y Densmore 2000) y con reducido ámbito de distribución, el valor de heterocigocidad registrada oscila entre $0.35( \pm 0.027)$ y $0.74( \pm 0.05)$ (Dever et al. 2002). La diversidad genética es necesaria para que las poblaciones (animales o vegetales) puedan adaptarse a los cambios ambientales (Frankham et al. 2002). Las tres poblaciones estudiadas mostraron poca heterocigocidad y por lo tanto un elevado porcentaje de homocigocis que puede producir en el futuro la expresión de genes deletéreos (Frankham et al. 2002) causando problemas a nivel individual y poblacional.

La baja heterocigocidad es el resultado de varios factores. Según Menzies y Kushlan (1991) las poblaciones del cocodrilo americano difieren en su genética cuantitativa debido posiblemente a razones de adaptación y por lo tanto los bajos niveles de variación genética en crocodílidos están determinados por el ambiente que los rodea. La baja diversidad genética estaría indicando pérdida de individuos por la selección ocasionada como una respuesta a factores ambientales (Gartside et al. 1977). En el Pacífico Central de Costa Rica, a la pérdida de cocodrilos por selección natural se suma la pérdida por selección artificial causada por la disminución de hábitat provocada por el aumento en el desarrollo humano de la zona estudiada (Anónimo 2001), y a la pérdida de individuos reproductores debido a la eliminación selectiva por parte de las personas que habitan cerca de 


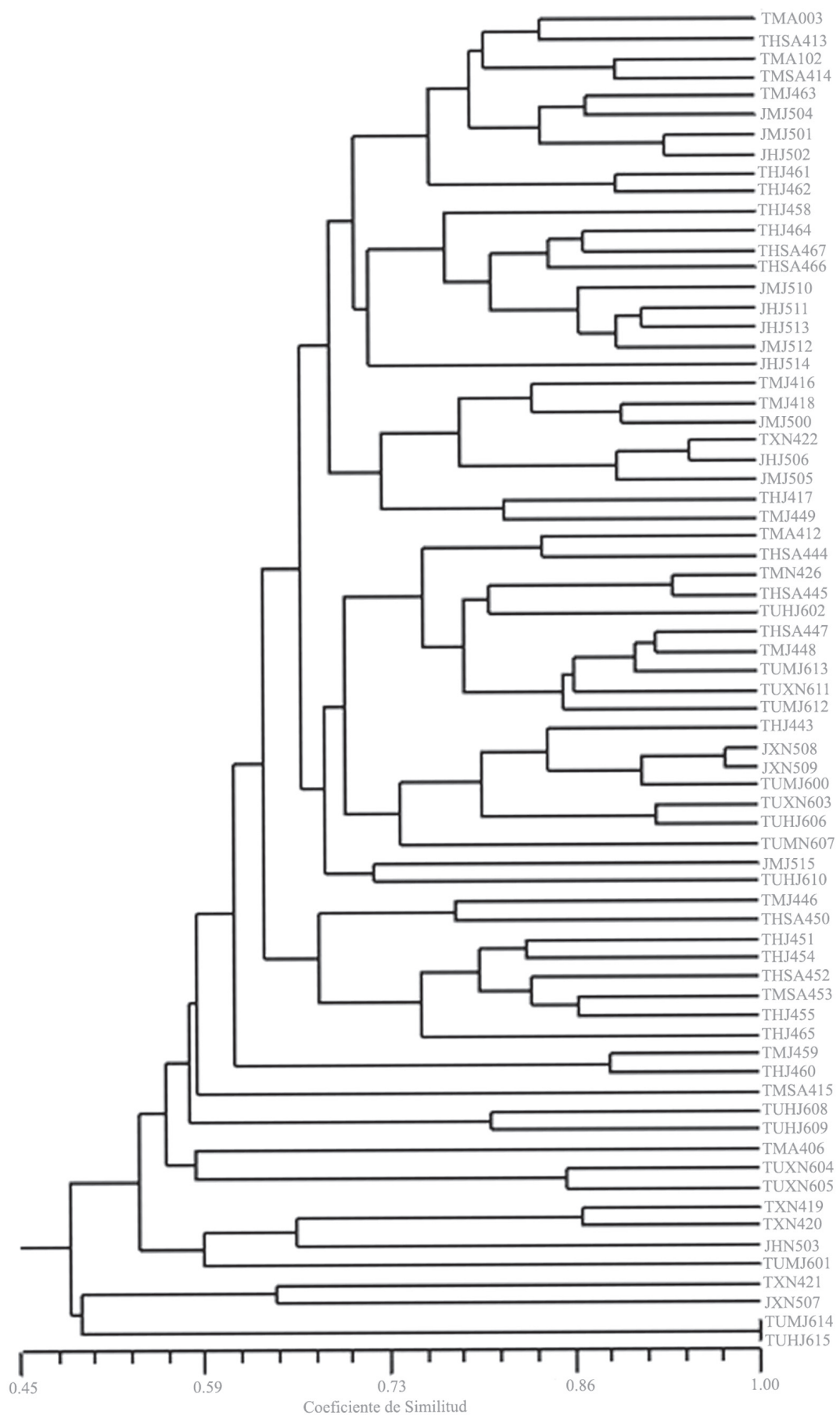

Fig. 2. Dendrograma SAHN basado en la similitud entre individuos de C. acutus. La letra inicial denota el origen del individuo, $\mathrm{J}=$ Jesús María, $\mathrm{T}=$ Tárcoles, $\mathrm{TU}=$ Tusubres.

Fig. 2. SAHN dendrogram based in the simility between individuals of C. acutus. The initial letter denote the origin of each individual, $\mathrm{J}=$ Jesus Maria, $\mathrm{T}=$ Tarcoles, $\mathrm{TU}=$ Tusubres. 
los ríos en los que se encuentran los cocodrilos (Chaves 1993, Jiménez 1998).

El valor de diferenciación genética entre poblaciones estimado para C. acutus $\left(\mathrm{G}_{\mathrm{ST}}=\right.$ $0.037)$ está por debajo del publicado para $C$. moreletii $\left(\mathrm{F}_{\mathrm{ST}}=0.062\right)$ por Dever et al. (2002), esto indica que no hay división entre las poblaciones estudiadas o sea, que existe movimiento de individuos entre las poblaciones y por lo tanto hay flujo genético constante (Dever et al. 2002). El número estimado de individuos que migran por generación $(\mathrm{Nm}=13.14)$ es superior al 5.15 registrado para $C$. moreletii en Belice (Dever et al. 2002) y está por encima de los valores publicados para la cascabel de Massasagua $(\mathrm{Nm}=2.6$, Sistrurus c. catenatus, Lougheed et al. 2000). Tomando en cuenta los valores de diversidad y diferenciación genética, puede pensarse que al haber un elevado movimiento de individuos la variabilidad genética de cada población es similar y esto causaría la poca variación entre las poblaciones. Esta situación podría causar constancia en el alto grado de homocigosis y a la vez ser el resultado de un periodo largo de estabilidad que ha mantenido a la población en equilibrio con su ambiente (Gartside et al. 1977), aunque este equilibrio sea a corto plazo (Chabreck 1967) debido a que esta condición evidencia una alta vulnerabilidad a cambios bruscos en el ambiente o en la dinámica de las poblaciones.

Tomando en cuenta el valor de flujo genético y el tamaño poblacional registrado por Porras (2004) para cada río, es probable que el movimiento de individuos se produzca principalmente desde el río Tárcoles hacia los ríos anexos, convirtiendo a esta población en la fuente de genes para este complejo metapoblacional, ya que cuenta con el tamaño mínimo viable y el tamaño efectivo (Primack 1993, Ross 1998, Piedra 2000, Frankham et al. 2002, Porras 2004) para garantizar la continuidad de la especie al menos a mediano plazo, por lo que la sostenibilidad a largo plazo de las tres poblaciones está determinada, entre otros factores, por la estabilidad de la población del río Tárcoles. No obstante, hay que recalcar que el flujo de genes en un sistema metapoblacional asume que cada población es igualmente accesible para las otras (Slatkin 1987) lo que significa que es esperable que también haya movimiento de individuos desde los ríos Jesús María y Tusubres, aunque esto no haya sido comprobado aún.

Las distancias genéticas entre las poblaciones son bajas y en este estudio tienen relación directa con la distancia geográfica. Los ríos Jesús María y Tusubres están más separados geográficamente y presentaron la mayor separación genética y entre las poblaciones de Jesús María y Tárcoles la interacción es más fuerte. Tomando en cuenta el valor de flujo de genes, diferenciación genética y distancia genética y geográfica, se puede considerar que la interacción de los individuos del río Tusubres con los otros dos es poca (Fig. 1) y/o que estos cocodrilos tengan una relación más estrecha con individuos de otras poblaciones aledañas.

Considerando lo anterior puede asumirse que se está presentando una dinámica metapoblacional entre los tres ríos estudiados, ya que según los argumentos teóricos (Yeh 2000), se comportan como una red de subpoblaciones con migración intermitente. Esta relación es más estrecha entre los ríos Jesús María y Tárcoles aunque la distancia genética que separa a estos dos del río Tusubres no es suficientemente amplia como para excluirlo. No debe descartarse el hecho de que las demás poblaciones de $C$. acutus que se encuentran entre los tres ríos estudiados y hacia el norte y sur de ellos, pueden estar formando parte de esta dinámica metapoblacional.

Los valores obtenidos en este trabajo no deben ser alarmantes ya que este trabajo está hecho a pequeña escala si se toma en cuenta la distribución total de la especie, también debe tomarse en cuenta que los individuos de los hábitat aledaños pueden mantener una dinámica estable entre las distintas subpoblaciones. De aquí se deriva la importancia de realizar estudios genéticos de C. acutus a lo largo de la distribución de la especie.

Para aumentar la variabilidad genética de estas poblaciones podría recurrirse a la translocación de hembras jóvenes (Robert et al. 2004) 
entre poblaciones con una comprobada diversidad genética. También se pueden reforzar las poblaciones por medio de cría en cautiverio y se puede considerar la opción de inseminar a las hembras de estas tres poblaciones y de aquellas que presenten una baja diversidad genética con semen de individuos que aporten material genético nuevo.

\section{AGRADECIMIENTOS}

Por la ayuda económica a Nacional Geographic Society, Programa Regional en Manejo de Vida Silvestre para Mesoamérica y el Caribe y Idea Wild. Por el apoyo técnico y logístico Jorge Madriz, Manfred Murrell y al Laboratorio de Biología Molecular de la Escuela de Ciencias Agrarias de la Universidad Nacional, a Miriam Hernández y Catalina Murillo del Laboratorio de Microbiología del Instituto Nacional de Biodiversidad, a Marco Vinicio Sánchez y Marco Tulio López. Por el apoyo logístico y colaboración en el trabajo de campo a Oldemar Pérez, Evangelista Alvarado y demás funcionarios del Parque Nacional Carara, Zona Protectora Tivives y Refugio Nacional de Vida Silvestre Playa Hermosa.

\section{RESUMEN}

Se utilizó la técnica de ADN Polimórfico Amplificado al Azar (RAPD) para analizar muestras de ADN de 70 individuos de C. acutus provenientes de los ríos Jesús María, Tárcoles y Tusubres en el Pacífico Central de Costa Rica para estimar la diversidad genética, la diferenciación entre poblaciones, el flujo genético y la distancia genética. La diversidad genética fue baja en los tres ríos $\mathrm{H}=0.2201$ en el río Jesús María, 0.2358 en el río Tárcoles y 0.2589 en el río Tusubres. La diversidad genética para el total de los individuos también fue baja, $H=0.2452$. Entre las tres poblaciones hay una dinámica metapoblacional $\left(\mathrm{G}_{\mathrm{ST}}\right.$ $=0.0367)$ principalmente en las poblaciones de los ríos Jesús María y Tárcoles. El valor de flujo genético $(\mathrm{Nm}=$ 13.1361) y el número de individuos registrado para cada río por Porras (2004) sugieren que la población del río Tárcoles está cumpliendo el papel de fuente y las de Jesús María y Tusubres constituyen los sumideros. Hubo relación directa entre la distancia genética y la distancia geográfica $(\mathrm{z}=$ $1.1449, r=0.9731, p<0.0010)$. Estos resultados indican la necesidad de diseñar una estrategia para la conservación de estos cocodrilos que considere la existencia de la metapo- blación entre los tres ríos y también es importante realizar un estudio genético en el resto de la costa Pacífica del Costa Rica y en todo el ámbito de distribución de esta especie.

Palabras clave: Crocodylus acutus, diversidad genética, flujo de genes, distancia genética, metapoblación.

\section{REFERENCIAS}

Anónimo. 1998. Ley de Conservación de la Vida Silvestre y su Reglamento. Investigaciones Jurídicas S. A. San José, Costa Rica.

Anónimo. 1999. Listas de Fauna de Importancia para la Conservación en Centroamérica y México. Sistema de Integración Centroamericana. San José, Costa Rica.

Anónimo. 2001. IX Censo Nacional de Población y V de Vivienda del 2000: Resultados Generales. Instituto Nacional de Estadística y Censos, San José, Costa Rica.

Bardakci, F. 2001. Random Amplified Polymorphic DNA (RAPD) Markers. Turk. J. Biol. 25: 185-196.

Blouin-Demers, G. \& P. J. Weatherhead. 2002. Implications of movement patterns for gene flow in black rat snakes (Elaphe obsoleta). Can. J. Zoolog. 80: 1162-1172.

Bohonak, A.J. 2002. IBD (Isolation By Distance): a program for analyses of isolation by distance. J Hered 93: 153-154.

Bolaños, J.R., J. Sánchez \& L. Piedra. 1997. Inventario y estructura poblacional de crocodílidos en tres zonas de Costa Rica. Rev Biol Trop 44/45: 283-287.

Chabreck, R.H. 1967. The American alligator-Past, present and future. Proc Ann Conf Southeastern Ass Game Fish Comm 21: 554-558.

Chaves, G. 1993. Situación poblacional del cocodrilo amarillo (C. acutus Reptilia, Crododilidae) en el Pacífico Central de Costa Rica. Repertorio Científico 2: $16-20$.

Chesser, R.K. 1991. Influence of gene flow and breeding tactics on gene diversity within populations. Genetics 129: $573-583$.

Davis L.M., T.C. Glenn, R.M. Elsey, I.L. JR Brisbin, W.E. Rhodes, H.C. Dessauer \& R.H. Sawyer. 2000. Genetic structure of six populations of American alligators: a microsatellite análisis. p. 38-50. In G. C. Grigg, F. Seebacher \& C. E. Franklin (eds.). Crocodilian Biology and Evolution. Surrey Beatty \& Sons, Chipping Norton, Australia. 
Dever, J., R. Strauss, T. Rainwater, S. McMurry \& L. Densmore. 2002. Genetic diversity, population subdivition and gene flow in Morelet's Crocodile (Crocodylus moreletti) from Belice, Central America. Copeia: 1078-1091.

Dice, L.R. 1945. Measures of the amount of ecologic association between species. Ecology 26: 297-302.

Fitzsimmons, N.N., S. Tanksley, M.R.J. Forstner, E.E. Louis, R. Gaglish, J. Gratten \& S. Davis. 2000. Microsatellite markers for Crocodylus: new genetic tools for population genetics, mating system studies ad forensics, p. 51-57. In G. C. Grigg, F. Seebacher \& C. E. Franklin (eds.). Crocodilian Biology and Evolution. Surrey Beatty \& Sons, Chipping Norton, Australia.

Flint, N.S., F.H. Van der Bank \& J.P. Grobler. 2000. A lack of genetic variation in commercially bred Nile crocodyles (Crocodylus niloticus) in the North-West Province of South Africa. Water SA 26: 105-110.

Frankham, R. 1996. Relationship of genetic variation to population size in wildlife. Conserv Biol 10: 15001508 .

Frankham, R., J.D. Ballou y D. A. Briscoe. 2002. Introduction to Conservation Genetics. Cambridge University, Cambridge, Reino Unido.

Gartside, D.F., H.C. Dessauer \& T. Joanen. 1977. Genic homozygosity in an ancient reptile Alligator mississipiensis. Biochem. Genet. 15: 655-664.

Hedrick, P. 2000. Genetics of Populations. Jones \& Bartlett, Sudbury, Massachusetts, EEUU.

Jiménez, Y.L. 1998. Crocodile attacks cause conservation crisis. CSG Newsletter 17: 8-9.

Konuma, A., Y. Tsumura, C.T. Lee, S.L. Lee \& T. Okuda. 2000. Estimation of gene flow in the tropical-rainforest tree Neobalanocarpus heimii (Dipterocarpaceae), inferred from paternity analysis. Mol .Ecol. 9: 18431852 .

Lougheed, S.C., H.L. Gibas, K.A. Prior \& P.J. Weatherhead. 2000. A comparison of RAPD versus Microsatellite DNA markers in population studies of de Massasauga Rattlesnake. J. Hered. 91: 458-463.

McDermott, J.M. \& B.A. McDonald. 1993. Gene flow in plant pathosystems. Annu. Rev. Phytopathol. 31: 353-373.
Menzies R.A. \& J.A. Kushlan. 1991. Genetic variation in populations of the American Crocodile. J. Herpetol. 25: $357-361$

Nei, M. 1978. Estimation of average heterozygosity and genetic distance from a small number of individuals. Genetics 89: 583-590.

Nei, M. 1987. Molecular Evolutionary Genetics. Columbia University. Nueva York, EEUU.

Norell, M.A. 1989. The higher level relationships of the extant crocodylia. J. Herpetol. 23: 325-335.

Parker, P., A. Snow, M. Schug, G. Booton \& P. Fuerst. 1998. What molecules can tell us about populations: choosing and using a molecular marker. Ecology 79: 361-382.

Piedra, L. 2000. Estado de las poblaciones de cocodrilos (Crocodylus acutus) (Reptilia: Crocodylidae) en tres ríos del Pacifico Central de Costa Rica. Tesis de Licenciatura, Universidad Nacional. Heredia, Costa Rica.

Porras, M.L.P. 2004. Situación actual del cocodrilo americano (Crocodylus acutus) en los ríos Jesús María, Tárcoles y Tusubres: estructura poblacional e intercambio genético. Tesis de Maestría, Universidad Nacional, Heredia, Costa Rica.

Primack, R. 1993. Essentials of Conservation Biology. Sinauer Assoc. Sunderland, Massachusetts, EEUU.

Ray, D.A., S. White, H.V. Duong, T. Cullen \& L. Densmore. 2000. High leves of genetic variability in West African Dwarf Crocodiles Osteolaemus tetraspis tetraspis, p. 58-63. In G. C. Grigg, F. Seebacher y C. E. Franklin (eds). Crocodilian Biology and Evolution. Surrey Beatty y Sons. Chipping Norton, Australia.

Robert, A., F. Sarrazin, D. Couvet \& S. Legendre. 2004. Releasing adults versus young in reintroductions: Interactions between demography and genetics. Conserv Biol 18: 1078-1087.

Rohlf, F.J. 2003. NTSYSpc: Numerical Taxonomy and Multivariate Analysis System. Exeter Software, Setauket, Nueva York, EEUU.

Ross, J.P. (ed.). 1998. Crocodiles: Status Survey and Conservation Action Plan. Crocodile Specialist Group. IUCN, Gland, Suiza.

Slatkin M. 1987. Gene flow and the geographic structure of natural popultions. Science 236: 787-792. 
Wu X., Y. Wang, K. Zhou, W. Zhu, J. Nie, C. Wang \& W. Xie. 2002. Genetic variation in captive population of Chinese alligator, Alligator sinensis, revealed by random amplified polymorphic DNA (RAPD). Biol Conserv 106: 435-441.

Yeh, F. \& T. Boyle. 1997. POPGENE 1.32. Molecular Biology and Biotechnology Center. University of Alberta, Center for International Forestry Research. Alberta, Canadá.
Yeh, F. 2000. Population Genetics, p. 21-37. En: A. Young, D. Boshier \& T. Boyle (eds.). Forest Conservation Genetics, Principles and Practice. CSIRO, Melbourne, Australia.

\section{INTERNET REFERENCE}

Anónimo. 2002. SREL DNA Lab. Second International Crocodilian DNA Workshop Abstracts (Revisado: 03 de octubre, 2002. http://www.uga.edu/srel/ CrocDNA\%20Web/CrocDNAabstracts. htm). 